\title{
Mechanisms underlying the weight loss effects of RYGB and SG: similar, yet different
}

\author{
A. Pucci ${ }^{1,2} \cdot$ R. L. Batterham ${ }^{1,2,3}$ \\ Received: 28 March 2018 / Accepted: 17 April 2018 / Published online: 5 May 2018 \\ (c) The Author(s) 2018
}

\begin{abstract}
The worldwide obesity epidemic continues unabated, adversely impacting upon global health and economies. People with severe obesity suffer the greatest adverse health consequences with reduced life expectancy. Currently, bariatric surgery is the most effective treatment for people with severe obesity, resulting in marked sustained weight loss, improved obesityassociated comorbidities and reduced mortality. Sleeve gastrectomy (SG) and Roux-en-Y gastric bypass (RYGB), the most common bariatric procedures undertaken globally, engender weight loss and metabolic improvements by mechanisms other than restriction and malabsorption. It is now clear that a plethora of gastrointestinal (GI) tract-derived signals plays a critical role in energy and glucose regulation. SG and RYGB, which alter GI anatomy and nutrient flow, impact upon these GI signals ultimately leading to weight loss and metabolic improvements. However, whilst highly effective overall, at individual level, post-operative outcomes are highly variable, with a proportion of patients experiencing poor long-term weight loss outcome and gaining little health benefit. RYGB and SG are markedly different anatomically and thus differentially impact upon GI signalling and bodyweight regulation. Here, we review the mechanisms proposed to cause weight loss following RYGB and SG. We highlight similarities and differences between these two procedures with a focus on gut hormones, bile acids and gut microbiota. A greater understanding of these procedure-related mechanisms will allow surgical procedure choice to be tailored to the individual to maximise post-surgery health outcomes and will facilitate the discovery of nonsurgical treatments for people with obesity.
\end{abstract}

Keywords Roux-en-Y gastric bypass $\cdot$ Sleeve gastrectomy $\cdot$ Gut hormones $\cdot$ Bile acids $\cdot$ Gut microbiota $\cdot$ Type 2 diabetes

$\begin{array}{ll}\text { Abbreviations } \\ \text { BA } & \text { Bile acids } \\ \text { BMI } & \text { Body mass index } \\ \text { CCK } & \text { Cholecystokinin } \\ \text { DPP4 } & \text { Di-peptidyl peptidase inhibitor } \\ \text { FGF-19 } & \text { Fibroblast growth factor-19 } \\ \text { FXR } & \text { Farnesoid X receptor } \\ \text { GI } & \text { Gastrointestinal } \\ \text { GIP } & \text { Glucose-dependent insulinotropic polypeptide } \\ \text { GLP-1 } & \text { Glucagon-like peptide-1 } \\ \text { OAGB } & \text { One anastomosis gastric bypass }\end{array}$

R. L. Batterham

r.batterham@ucl.ac.uk

1 Centre for Obesity Research, Rayne Institute, University College London, London, UK

2 Centre for Weight Management and Metabolic Surgery, University College London Hospital Bariatric, London, UK

3 National Institute of Health Research, University College London Hospital Biomedical Research Centre, London, UK

$\begin{array}{ll}\text { PYY } & \text { Peptide YY3-36 } \\ \text { RCT } & \text { Randomised clinical trial } \\ \text { RYGB } & \text { Roux-en-Y gastric bypass } \\ \text { SG } & \text { Sleeve gastrectomy } \\ \text { T2D } & \text { Type 2 diabetes }\end{array}$

\section{Introduction}

The prevalence of obesity continues to increase unabated. Globally in 2014, approximately $52 \%$ of the adult population were overweight (1.9 billion) or obese (>600 million) [1] . Obesity increases mortality and its associated comorbidities including cardiovascular disease, type 2 diabetes (T2D) and some cancers, and represents a major health and economic burden.

Bariatric surgery is recognised as the most effective treatment for people with severe obesity, defined by a body mass index (BMI) equal to or greater than $40 \mathrm{~kg} / \mathrm{m}^{2}$, or greater than $35 \mathrm{~kg} / \mathrm{m}^{2}$ in the presence of obesity-related 
complications [2]. Bariatric surgery involves surgical modifications of the gastrointestinal (GI) tract anatomy with a consequent alteration of nutrient flow affecting GI biology [3]. Many clinical trials have demonstrated the superiority of bariatric surgery in terms of efficacy and sustainability of weight loss and resolution of obesity-related comorbidities when compared with intensive medical and lifestyle interventions [4-6].

The concept of bariatric surgery emerged during the 1950s when procedures that involved small intestine resection were noted to result in weight loss [7-9]. The first bariatric procedures were, therefore, designed to specifically induce weight loss through pure malabsorption somewhat predictably these procedures led to severe nutritional deficiencies and metabolic consequences. From the observation that patients undergoing gastric resection and/or bypass for peptic ulcer disease tended to lose weight, Mason and colleagues performed the first gastric bypass procedure in 1967 $[10,11]$. This procedure combined reduced stomach capacity (restriction) and decreased digestion forming the basis for subsequent "malabsorptive" and "restrictive" procedures [10]. However, 50 years on, it is now accepted that most bariatric procedures engender weight loss and metabolic improvements by mechanisms other than restriction and/or malabsorption.
Over the past decade, the effectiveness of bariatric surgery has resulted in a marked increase in the number of procedures undertaken worldwide, with approximately 580,000 operations performed in 2014 [12]. The surgical procedures undertaken are continuously evolving, based on technical advances, efficacy data, short-term and longterm complication rates, and increased understanding of the physiology underpinning their success. Currently, the most common procedures undertaken globally are sleeve gastrectomy (SG) (45.9\%) and Roux-en-Y gastric bypass (RYGB) (39.6\%), and these two procedures form the focus of this review. Purely restrictive procedures, such as adjustable gastric banding, are now less commonly performed (7.4\%) [12] (Fig. 1).

Despite the increasing use of bariatric surgeries, the underlying mechanisms remain incompletely understood. Post-operative weight loss is highly variable [13] and many studies suggest that the total amount of weight loss plays a major role in determining glycaemic improvements and remission of comorbidities after surgery [14]. Given the difficulty of accessing bariatric surgery in many countries, it is crucial to identify patients who may benefit the most from surgery and to tailor the surgical procedure to the individual patient to maximise health outcomes. To achieve this aim, we need to gain a greater understanding of the mechanisms underlying the sustained weight loss produced by bariatric surgery, procedure-related
Fig. 1 Schematic diagram illustrating the normal upper GI anatomy (a) and the two most commonly performed bariatric surgical procedures in the world with relative percentages. The metabolic procedures: $\mathbf{b}$ RYGB and $\mathbf{c}$ SG (surgical technique described in details in the main text). RYGB were the $39.6 \%$ and SG were the $45.9 \%$ of the total procedures performed in 2014 [12]. RYGB Roux-enY gastric bypass, $S G$ Sleeve gastrectomy

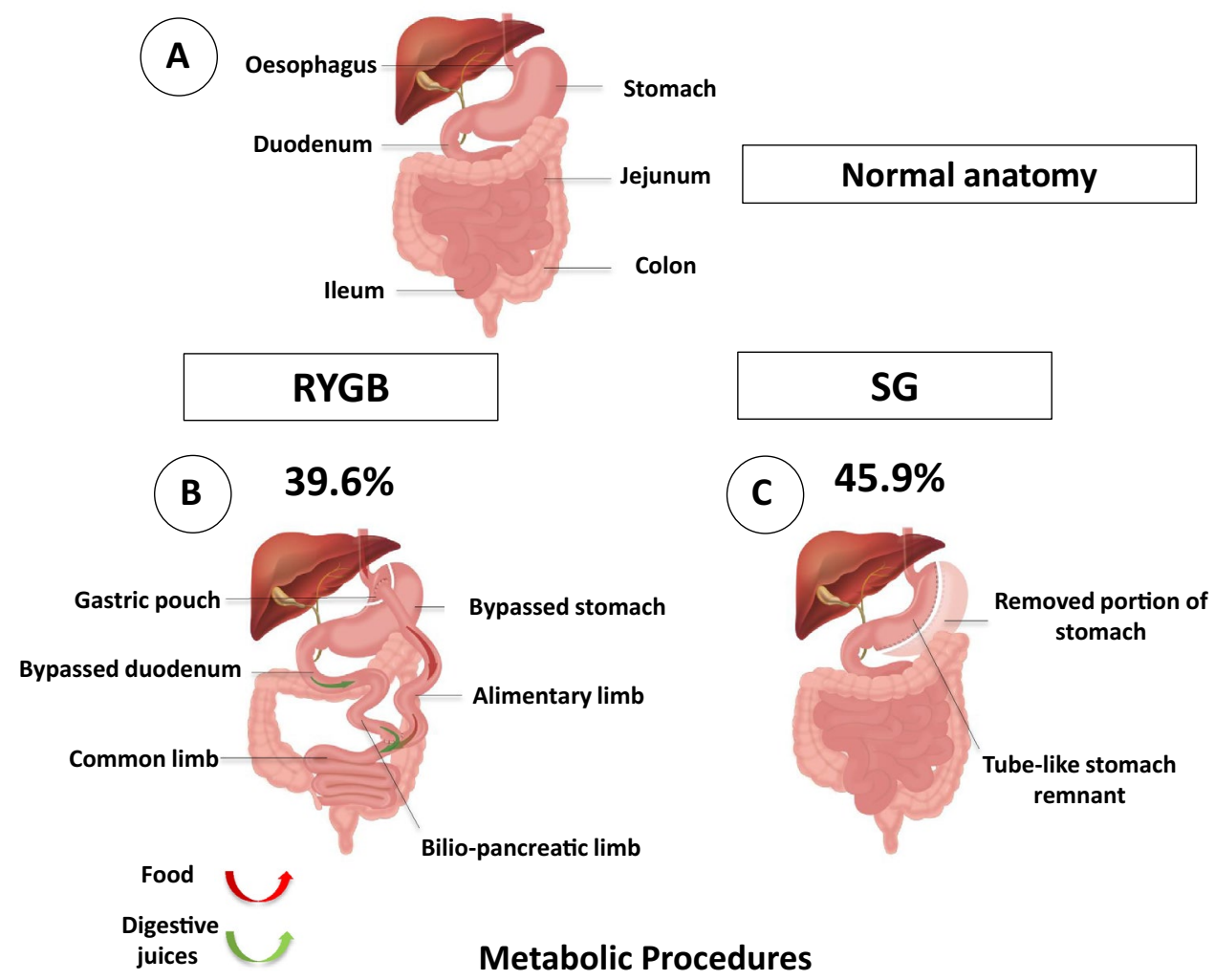


differences and how these interact with the patient's biology. This review provides an overview of mechanisms, suggested to contribute to weight loss after RYGB and SG.

\section{Roux-en-Y gastric bypass}

In RYGB, the stomach is divided generating a small gastric pouch $(20-30 \mathrm{~mL})$, which is then anastomosed with the mid-jejunum, creating the Roux or alimentary limb. Ingested nutrients thus bypass most of the stomach, duodenum, and the proximal jejunum. Anastomosis of the biliopancreatic limb with the jejunum allows drainage of bile acids (BA) and pancreatic secretions, which mix with the nutrients in the jejunum (common limb) [15] (Fig. 1). A technically easier version of the standard RYGB, the one anastomosis gastric bypass (OAGB) is gaining favour (approximately 10,400 procedures worldwide in $2014,1.8 \%$ of all bariatric procedures) but mechanistic studies and long-term outcome studies are awaited and OAGB will not be part of this review [12].

\section{Sleeve gastrectomy}

Sleeve gastrectomy (SG), was initially performed as a firststage procedure to reduce weight in patients with a BMI of greater than $50 \mathrm{~kg} / \mathrm{m}^{2}$ and was intended as a purely restrictive procedure. However, the significant sustained weight loss and metabolic benefits obtained by SG led to its adoption as a standalone procedure. SG involves transection along the greater curvature creating a tube-like new stomach removing the fundus and body [16] (Fig. 1). Gastric contents pass rapidly into the duodenum. SG has become the most common bariatric procedure because of the easier technique, shorter operation time, fewer surgical and nutritional complications, and similar short-term weight loss and clinical outcomes compared with RYGB [12].

\section{Weight loss and metabolic benefits after RYGB and SG}

It has been clearly demonstrated that bariatric surgery is an effective treatment for severe obesity engendering marked weight loss, sustained in the long term when compared to calorie-restricted dieting. The 20-year outcome data from the Swedish Obese Subjects (SOS) study showed that patients who received bariatric surgery achieved a significantly greater mean body weight reduction of approximately $18 \%$ compared with approximately $1 \%$ in patients who received standard medical treatment through their local health centres [5]. RYGB patients were able to maintain more than $25 \%$ of their total weight loss after 20 years (SG was not performed yet when the study started) [5]. Multiple retrospective uncontrolled observational studies and also randomised clinical trials (RCTs) have demonstrated the superiority of bariatric surgery both in terms of weight loss outcomes and resolution of comorbidities when compared with intensive medical and lifestyle interventions $[4,17]$. The 5 -year results from the STAMPEDE RCT, which recruited patients with obesity and T2D, clearly showed how bariatric surgery was more effective than intensive medical therapy in inducing weight loss and in decreasing, or even resolving, hyperglycemia [4].

A limited number of RCTs have compared the efficacy of RYGB against SG with regards to weight loss outcomes and resolution of obesity-related comorbidities, especially T2D. The STAMPEDE trial, which was not powered to detect differences between procedures, reported that RYGB was associated with greater weight loss and a need for fewer T2D medications after 5 years compared with SG. This is interesting considering that 3-year results from the same authors and from other short-term studies showed similar results for the two procedures [17-19]. The SMBOSS RCT reported no significant weight loss difference between the two procedures at 5 years post-surgery [20]. The 5 -year results from the SLEEVEPASS RCT showed how, although not statistically significant, RYGB was associated with greater weight loss, T2D remission, discontinuation of medications for dyslipidaemia and hypertension, the latter reaching statistical significance [21]. The 5-year results from the Strasbourg RCT confirmed this trend showing that RYGB resulted in more stable weight loss when compared to SG [22]. Furthermore, a recent meta-analysis including 15 RCTs reported that RYGB may provide a greater degree of weight loss at $2-5$ years post-operatively compared with SG [23]. Interestingly, the difference in weight loss between RYGB and SG groups increased with time. Another small 2-year RCT reported that despite similar weight loss results, RYGB reduced truncal fat compared to $\mathrm{SG}$. This differential impact upon truncal fat might in part explain why RYGB leads to greater glycaemic improvement than SG despite similar weight loss. However, larger studies are needed to investigate this finding [24].

\section{The physiology of body weight regulation}

Feeding behaviour is determined by homeostatic and reward-related brain centres that continually integrate peripheral signals relating to energy stores and nutrient availability [25] (Fig. 2). Obesity results when energy intake chronically exceeds energy expenditure, which in 


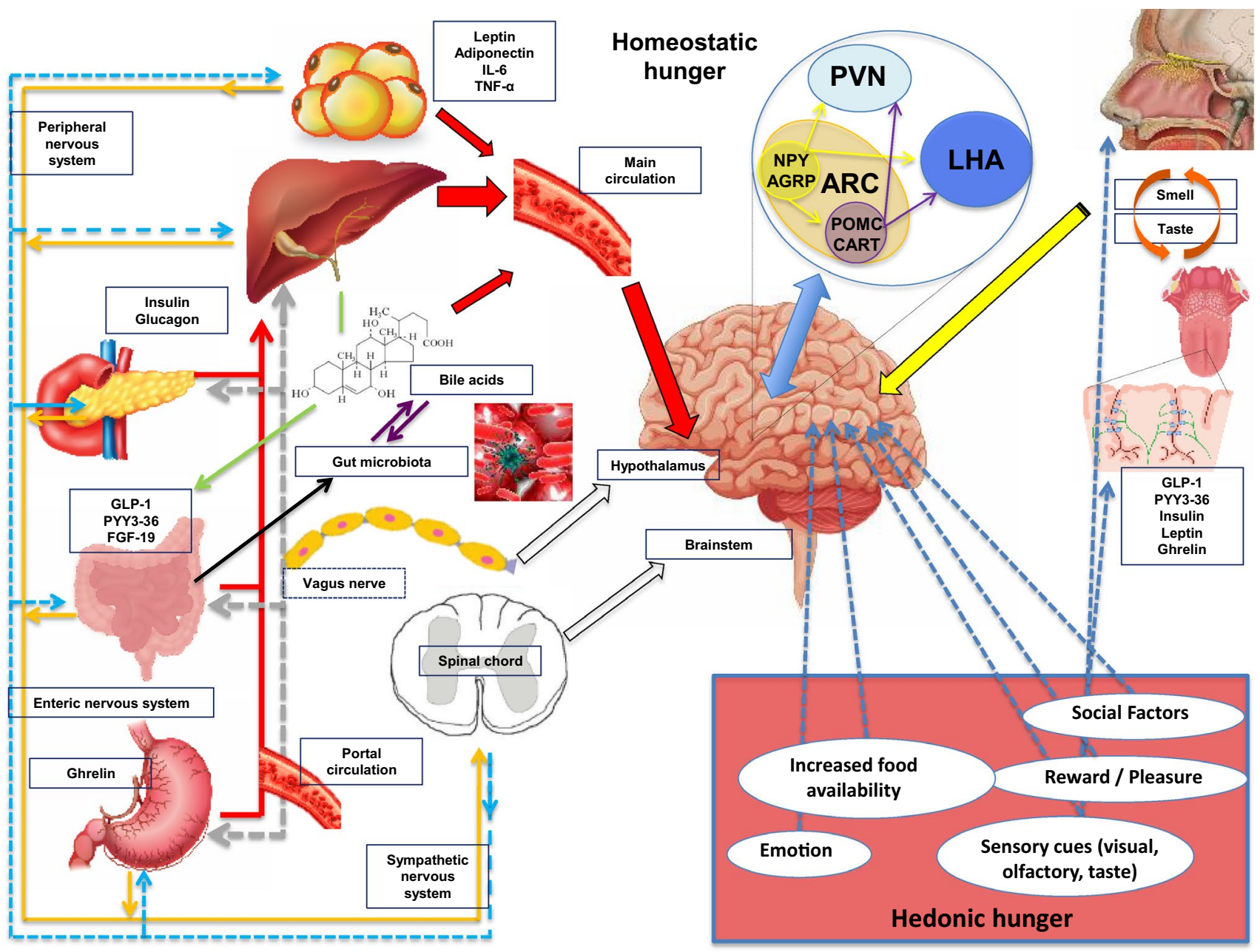

Fig. 2 Schematic diagram illustrating the mechanisms involved in regulating feeding behaviour. Nutrient entry into the GI tract causes stomach and intestine distension, secretion of pancreatic enzymes and BA, altered enteric and vagal nerve signalling and exposure of gut enteroendocrine cells to nutrients with altered circulating gut hormone levels (e.g. decrease in orexigenic hormone ghrelin and increase in anorectic hormones PYY3-36 and GLP-1). Gut-derived signals (nutrients, hormones, and neural) and adipokines (e.g. leptin, IL-6, TNF-alpha and adiponectin) act directly and indirectly upon brainstem and hypothalamic arcuate nuclei (first order neurons: orexigenic NPY/AgRP and anorexigenic POMC/CART). ARC neurons interact with second order neurons in the PVN, and to the LHA. All those mechanisms are involved in the regulation of homeostatic

turn may be due to an alteration of the homeostatic or hedonic system or both [26]. Peripheral energy signals are classified as long term, such as leptin and insulin, which provide information regarding energy stores and short term, including nutrient and meal-derived energy availability messages [25]. Gut hormones are secreted from the GI enteroendocrine cells in response to nutrient ingestion and act as regulators of energy balance and glucose homeostasis [27]. The gut hormones, peptide YY3-36 (PYY) and glucagon-like peptide-1 (GLP-1), are hunger. Social factors, emotion, reward, pleasure, increased food availability and sensory cues can influence brain reward and higher cognitive brain regions leading to altered feeding behaviour (hedonic hunger). Taste and olfactory signals can also influence energy intake acting on both homeostatic and brain reward systems. Insulin leptin, GLP-1, PYY and ghrelin are present in saliva with cognate receptors on taste buds and olfactory neurons. AgRP agouti-related peptide, $A R C$ arcuate nucleus, CART cocaine and amphetamine-regulated transcript, FGF-19 fibroblast growth factor-19, GLP-1 glucagon-like peptide 1, IL-6 interleukin-6, LHA lateral hypothalamic area, $N P Y$ neuropeptide $\mathrm{Y}, P N S$ peripheral nervous system, $P V N$ paraventricular nucleus, $P Y Y 3-36$ peptide tyrosine-tyrosine 3-36, $P O M C$ pro-opiomelanocortin, SNS sympathetic nervous system

secreted from enteroendocrine $\mathrm{L}$ cells present throughout the GI tract, in response to nutrient ingestion [27, 28]. Both PYY and GLP-1 have an appetite-suppressing effects, modulating neural activity within homeostatic and reward brain regions [28-30]. In addition, both PYY and GLP-1 impact upon glycaemic regulation [31]. GLP-1 is one of the key mediators of the incretin effect (the augmentation of insulin secretion after oral as opposed to intravenous administration of glucose) [29]. Furthermore, 
GLP-1-based medications are used to treat people with T2D and more recently obesity [32].

In contrast to the anorectic actions of PYY and GLP-1, ghrelin, produced primarily by P/D1 cells in oxyntic glands in the gastric fundus, stimulates appetite and energy intake. Circulating ghrelin levels increase in the fasted state and decrease post-prandially proportionally to the amount of ingested food [33]. Ghrelin also acts on homeostatic and reward centres, and elevations of ghrelin levels can enhance the hedonic responses to eating [34].

BA are produced in the liver, stored in the gallbladder and secreted into the duodenum upon nutrient ingestion. Their main role is the facilitation of micelle formation promoting the digestion of dietary fat and fat-soluble vitamins. More recently, BA have also been shown to play a role in regulating glucose and energy homeostasis [35]. BA activate GLP-1 secretion via activating G protein-coupled receptors (TGR5) on L cells and fasting total circulating BA levels are positively correlated with postprandial GLP-1 levels [36]. BA also act on farnesoid X receptor (FXR) present in pancreatic $\beta$ cells increasing insulin release [37]. BA activation of intestinal FXR cells stimulates the secretion of fibroblast growth factor-19 (FGF-19), a protein that contributes to improved peripheral glucose disposal and lipid homeostasis leading to reduced weight and increased metabolic rate [38, 39]. In animal studies, BA supplementation has been shown to reduce weight gain, [40] and postprandial BA levels are inversely related with body fat mass [41]. Thus, the physiologic effects of BA likely extend beyond the gut and pancreas with TGR5 receptors also located on skeletal muscle.

The human gut hosts trillions of microorganisms [42]. Gut microbiota can affect energy absorption, through altering intestinal mucosal permeability, energy expenditure by intracellular thyroid hormone activation via FXR signalling [40] and immunologic systems of their human hosts [43]. Diet, antibiotic exposure and other environmental

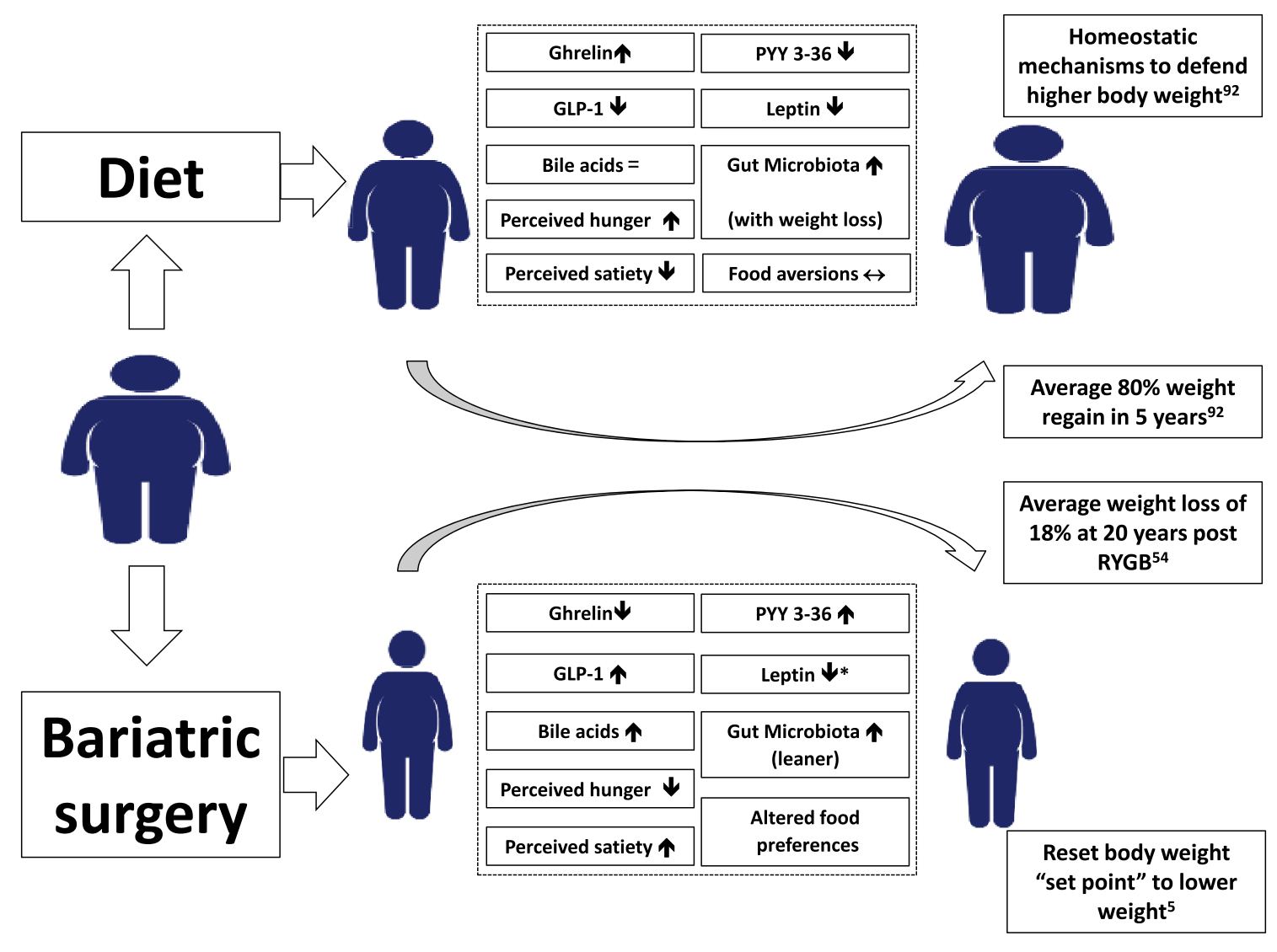

Fig. 3 Schematic diagram illustrating the different biological changes induced by weight loss obtained through dieting (upper part) compared to bariatric/metabolic surgery (lower part). Powerful compensatory biological changes contribute to the high rate of weight recidivism observed following lifestyle intervention weight management. Many homeostatic mechanisms act to defend higher body weight, and these includes hormonal alterations and a decreased energy expenditure leading to increased hunger and energy consumption. In contrast, bariatric surgery leads to a favourable biology that includes increased satiety hormones, reduced ghrelin, enhanced BA secretion and a "lean" microbiota. Together these mechanisms lead to reduced hunger and a shift towards healthier food options with a resetting of body weight "set point" to a lower level facilitating meaningful and sustained weight loss. GLP-1 glucagon-like peptide 1, PYY3-36 peptide tyrosine-tyrosine 3-36. *Suggestion that leptin sensitivity may improve References for this figure [5, 60, 96] 
factors can in turn affect the diversity of the microbiota and their function [43].

Taste and olfactory signals can impact on energy intake by influencing food selection [44]. There is a close interaction between signals of energy homeostasis, and taste and smell. Insulin leptin, GLP-1, PYY and ghrelin have been found in saliva and their cognate receptors identified on taste buds and olfactory neurons [44]. Rewarding foodrelated sensory stimuli can override satiety signals leading to excess energy intake. The latter leads to deregulation of the homeostatic mechanisms that normally control body weight predisposing individuals to gain more weight [34] (Fig. 3).

\section{The obese state: pathophysiologic changes}

Obesity is the result of a chronic positive energy balance [45]. Once the obese state is fully established, many pathophysiologic changes occur including leptin and insulin resistance together with reduced circulating plasma PYY and GLP-1 levels in response to nutrient ingestion. The postprandial suppression of circulating ghrelin is also reduced. Obesity has also been shown to blunt the rise in circulating postprandial BA levels [46].

A dysbiotic relationship between host and microbiome has been suggested to contribute to the development of obesity [47], with profound differences found between the microbiome composition of obese and lean individuals [48]. Obesity is associated with the relative increase or reduction of certain bacterial species and the importance of the relative proportions of those species remains an area of active investigation. Transplantation of gut bacteria from obese mice to normal weight germ-free mice results in weight gain in the recipients [49]. Conversely, faecal transplantation from lean human donors to recipient patients with metabolic syndrome led to improvements in insulin sensitivity. A dysbiotic relationship may affect host energy and nutrient metabolism altering intestinal mucosal permeability, promoting increased fat storage in adipose tissue [50], by enhancing the absorption of shortchain fatty acids derived by otherwise indigestible luminal polysaccharides and by triggering inflammatory responses through a process referred to as "metabolic endotoxemia" $[51,52]$.

The neural response to food cues is altered in people with obesity compared to people with normal weight. This has been confirmed by brain-imaging studies showing an increased stimulation of central reward pathways in response to eating or food cues [26]. In addition, there is evidence that eating behaviour in people with obesity becomes dissociated from perceptions of satiety and hunger [53, 54].

\section{Biological changes that favour weight recidivism following lifestyle interventions}

Lifestyle interventions lead to weight loss. However, people with overweight and obesity find it very hard to maintain this weight loss in the long term. In response to weight loss, which throughout evolution would have been a threat to survival, multiple powerful biological changes occur that lead to increased hunger, enhanced neural responses to food cues and heightened drive to consume energy-dense foods. Compensatory changes include decreased energy expenditure, due to reduced lean muscle mass and reduced sympathetic activity [55], reduced circulating leptin, GLP-1 and PYY levels with increased ghrelin levels [54], and altered brain neural response to food cues. Impaired circulating BA levels, an altered gut microbiome, and decreased vagal signal transmission are also described [56]. These changes are summarised in Fig. 3 and contribute to the high rate of weight recidivism observed following lifestyle intervention weight management programmes [57].

\section{Biological changes that favour sustained weight loss following SG and RYGB}

The multifactorial mechanisms promoting weight loss following RYGB/SG remain incompletely understood. However, it is clear that the beneficial effects are not achieved through malabsorption and restriction alone [58, 59]. Reduced energy intake, as a result of altered eating behaviour, is recognised as the main driver for weight loss. In contrast to the compensatory biological changes that are seen following weight loss induced by lifestyle interventions, SG and RYGB are associated with reduced hunger and reduced neural responsiveness to food cues. Moreover, food becomes less rewarding and there is a shift in preference from energydense food rich in fat and sugar to healthier options enabling patients to adopt a favourable eating behaviour [60] (Fig. 3). These changes in eating behaviour are the result of multiple mechanisms, some of which are common to both SG and RYGB, and others that are procedure specific. These are summarised in Fig. 4.

\section{RYGB and SG impact on GI-derived signals}

\section{Gut hormones}

In contrast to the unfavourable gut hormone changes that accompany weight loss induced by lifestyle intervention, RYGB and SG are associated with reduced ghrelin levels 


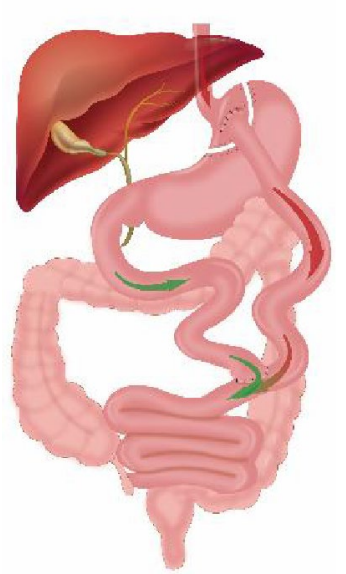

RYGB

\begin{tabular}{|c|c|c|}
\hline+ & Calorie restriction & + \\
\hline$\uparrow$ & Vagal nerve signaling & 个 \\
\hline+ & Taste and smell changes & + \\
\hline+ & Food aversions & + \\
\hline$\downarrow$ & Ghrelin & $\downarrow \downarrow$ \\
\hline$\uparrow$ & Bile acid secretion & $\uparrow$ \\
\hline$\uparrow$ & Intestinal glucose uptake & \\
\hline+ & Fat malabsorption & \\
\hline ヘト & GLP-1 & $\uparrow$ \\
\hline 个ト & PYY3-36 & $\uparrow$ \\
\hline$\downarrow$ & GIP & \\
\hline$\uparrow$ & Oxyntomodulin & \\
\hline ヘト & FGF-19 & $\uparrow$ \\
\hline$\uparrow$ & CCK & $\uparrow$ \\
\hline$\downarrow$ & Gastrin & $\uparrow$ \\
\hline$\uparrow$ & Neurotensin & \\
\hline
\end{tabular}

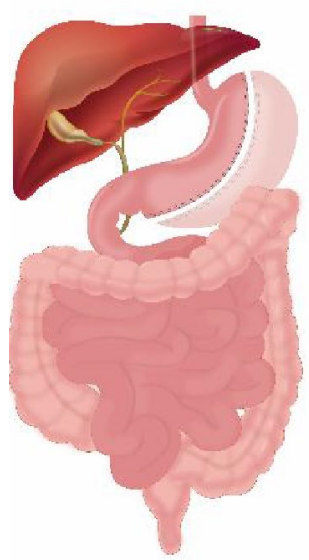

SG
Fig. 4 Schematic diagram illustrating RYGB and SG and the mechanisms leading to weight loss and resolution of comorbidities. For every mechanism the effect of the procedure is represented with a " $\uparrow$ " when stimulating or " $\downarrow$ " when suppressing. A " + " means that the proposed mechanism is present only after surgery when compared to the pre-operative period. When the effect is stronger for one of the two

and increased circulating meal-stimulated PYY and GLP-1 levels. These gut hormone changes precede and are independent from weight loss and are sustained up to 10 years post-operatively [61, 62].

\section{Ghrelin}

Since the landmark publication by Cummings et al. [63] showing that circulating ghrelin levels rose with calorierestricted diets but are markedly reduced post-RYGB, many studies have focused their attention on investigating the role of gut hormones as mediators of the beneficial effects of surgery. Whilst some controversy exists regarding post-RYGBcirculating ghrelin levels, these differences most likely reflect methodological variability, duration after surgery and sample processing techniques [64]. SG leads to sustained and greater reduction in circulating acyl-ghrelin levels than RYGB because of the removal of the fundus of the stomach where most ghrelin-producing cells are located [62].

\section{GLP-1 and PYY}

Following RYGB, nutrient-stimulated circulating levels of PYY and GLP-1 are markedly elevated, most likely as a result of increased nutrient stimulation of $L$ cells as procedures there is a double arrow compared with a single one. When the effect is missing for one procedure it means that the mechanism is procedure specific. $R Y G B$ Roux-en-Y gastric bypass, $S G$ Sleeve gastrectomy, GLP-1 glucagon-like peptide 1, PYY3-36 peptide tyrosinetyrosine 3-36, GIP gastric inhibitory polypeptide, FGF-19 fibroblast growth factor-19, $C C K$ cholecystokinin

a consequence of anatomical rearrangement. SG leads to rapid gastric emptying and enhanced exposure of $L$ cells to nutrients with increased nutrient-stimulated PYY and GLP-1 levels, but to a lesser extent than following RYGB.

Patients with poor post-operative weight loss reported increased subjective hunger and lower satiety levels coupled with lower circulating PYY, GLP-1 and higher ghrelin, when compared with people with good weight loss [65]. These findings imply that gut hormones may play a causal role in mediating weight loss following RYGB and SG. This hypothesis is supported by three lines of evidence: first, the administration of the somatostatin analogue octreotide to people following RYGB leads to increased appetite and energy intake, and weight gain [66]; second, combined administration of di-peptidyl peptidase inhibitor (DPP4) inhibitor and exendin 9-39 (inhibiting the formation of PYY3-36 and blocking GLP-1 action) leads to increased food intake after RYGB [67]; and third profound anorexia and excessive weight loss post-SG have been shown to be associated with markedly elevated circulating fasted and post-meal PYY levels [68]. 


\section{Other gut hormones}

Other gut hormones with effects on feeding behaviour have also been studied. However, the extent of their role in mediating the beneficial effects of RYGB and SG are unclear. For completeness, we have summarised these below:

Glucose-dependent insulinotropic polypeptide (GIP) is an incretin peptide hormone secreted by K-cells in the proximal small intestine. GIP increases postprandial glucagon secretion, intestinal glucose absorption and storage of fatty acids in adipose tissue [69]. Previous studies have suggested that patients with T2D are resistant to the effects of GIP and this GIP resistance has precluded the development of GIP-based T2D therapies. Following RYGB, a reduction in postprandial GIP levels has been reported [70, 71], most likely as a consequence of the K-cells being bypassed. In addition, a restoration of GIP sensitivity has also been suggested [71]. The effects of SG on circulating GIP levels have not been studied sufficiently.

Oxyntomodulin, a pro-glucagon-derived peptide with anorectic effects, is increased early after RYGB [27]. This effect has not been documented after SG.

Cholecystokinin (CCK), another anorexigenic hormone, has been suggested to act synergistically with leptin, and amylin, a pancreatic hormone co-secreted with insulin [72]. Increased levels of CCK following RYGB and SG have been reported. In one study, SG was associated with a larger CCK increase compared to the RYGB [73].

Gastrin is a peptide hormone that stimulates the secretion of gastric acid from the parietal cells of the stomach, aids in gastric motility and reduces appetite. There is some evidence suggesting that postprandial gastrin levels fall after RYGB [74] while SG may be associated with increased levels [75].

Neurotensin is co-expressed in enteroendocrine cells with GLP-1 and PYY. Circulating neurotensin levels increase after RYGB and have also been proposed to contribute to eating behaviour changes post-RYGB [76].

Additional gut hormones, such as ileal-derived FGF-19, (discussed below) may also contribute to weight loss and metabolic changes following bariatric surgery.

\section{Bile acids}

Following RYGB and SG, changes in circulating BA levels and composition are reported and these changes are suggested to contribute to weight loss and improved glucose metabolism. Indeed, in animal models, rerouting bile to the distal small bowel by transposing the common bile duct results in improved body weight, glucose metabolism, and hepatic steatosis, and increases in plasma BA similar to those seen after RYGB. Despite their anatomical differences,
RYGB and SG exert similar effects on BA, altering both their composition and circulating concentrations; however, the changes observed following SG are more modest [35, 77]. The exact mechanism responsible for elevated $\mathrm{BA}$ is unclear following RYGB and SG, but animal work suggests that an accelerated nutrient flow to the distal small intestine is a key mechanism [78]. The rise in circulating BA levels appears even greater several months post-operation and intestinal cellular adaptations may play a major role in explaining elevated postprandial BA levels [79]. These changes could be due to increased hepatic synthesis or altered enterohepatic recirculation of bile, or both. Metabolic procedures may also alter intestinal gut microbiota, which are key regulators of BA conjugation and secondary BA formation [80]. Post-surgery increased BA diversity might also impact on GLP-1 secretion and energy expenditure. Binding of BA TGR5 receptors in skeletal muscle and brown adipose tissue may contribute to an enhanced action of thyroid hormones by increasing energy expenditure [81]. Therefore, BA could contribute to weight loss and metabolic improvements after bariatric surgery through independent and dependent regulatory mechanisms. In RYGB subjects, bacterial overgrowth in the biliopancreatic limb may generate secondary BA species with differing affinity for FXR or TGR5 and different metabolic effects [82]. FXR gene knockout mice regained weight lost after SG, suggesting that the FXR plays a key role in mediating weight loss and metabolic improvements after SG [81]. Whether FXR signalling and/ or FGF-19 contributes to the beneficial effects of bariatric surgery in humans is uncertain at present. Finally, a study measured serum BA levels before and after bariatric surgery showed that they were significantly increased only at 1-year post-surgery; whereas, the substantial increase in PYY and GLP-1 levels could be observed as soon as 1-week postsurgery. This finding shows that increased plasma BA may not contribute to the early metabolic improvements observed after bariatric surgery [77]. Weight-loss surgery can also affect the interplay between BA and gut microbiota, which can contribute to the metabolic effects observed in the postoperative period [83].

\section{Gut microbiota}

Following RYGB and SG, the intestinal microbiome is altered. Animal studies with faecal transplant from RYGBtreated to germ-free mice resulted in significantly greater weight loss suggests that the altered microbiome per se contributes to weight loss [84]. Significant differences exist between the rodent and the human microbiome, and the strict relationship between microbiome and BA in humans remains to be clarified. The profound post-surgical changes in the microbiome are probably the result of anatomical, 
dietary and systemic changes (weight loss). In rodents, these changes can be detected as early as 7 days after RYGB [80], with similar patterns observed in humans [85]. The specific and procedure-related mechanisms responsible for post-surgery gut microbiota changes remain to be delineated [86]. In a recent study, Murphy and colleagues found that RYGB produces greater and more favourable changes in gut microbiota functional capacity than SG [87], at 1-year post-operatively, despite similar weight loss. Another study by Medina confirmed a differential effect of RYGB and SG on gut microbiota species despite equal weight loss [88]. SG seems to have fewer effects on the intestinal microbiota compared to RYGB, consistent with another study carried out in rodents [89]. This could be due to the lesser physical manipulations of the intestinal tract of SG compared to RYGB. It is difficult to conclude that gut bacteria are essential for the effects of metabolic procedures, but we can conclude that changes in gut microbiota induced by RYGB are sufficient to produce weight loss [83].

\section{Other mechanisms}

\section{Enteroplasticity}

Enteroplasticity refers to the post-surgical adaptations, including remodelling of the intestinal mucosa, morphologic changes, and altered innervation [35]. There is evidence that L cells proliferate following RYGB and SG and that L cells exhibit increased nutrient sensitivity, releasing more PYY and GLP-1 for a given nutrient stimulant [90].

\section{Glucose uptake}

RYGB was recently reported to enhance SGLT1-dependent intestinal glucose uptake in the common limb and utilisation, leading to overall improvements in systemic glucose control [91]. Whether this alteration in glucose absorption is sufficient to affect whole-body glucose use, gut hormones secretion or weight loss remains uncertain [92].

\section{Taste and smell}

Post-surgery change in appetite, taste and smell may contribute to food preference changes following RYGB and SG. Interestingly, early data suggest that RYGB and SG may differentially impact upon subjective changes in appetite, taste, olfaction and food aversion post-operatively. Large longitudinal studies combining subjective and objective measures of taste and olfaction are warranted to detect possible procedures-related effects [93].

\section{Vagus nerve}

Afferent vagal nerve fibres in the stomach are sensitive to mechanical stretch related to food ingestion and signal to the brain [94]. Following RYGB, vagal fibres to the gastric pouch remain largely intact [95], whereas SG removes this pathway. Moreover, neurophysiological studies suggest that vagus nerve signalling also increases post-RYGB [56] and these changes may reduce food intake. These adaptations may contribute to the sustained metabolic effects of bariatric surgery.

\section{Conclusion}

Bariatric surgery is the most effective weight loss strategy for people with severe obesity leading to reduced mortality and improvement in obesity-associated comorbidities. However, although bariatric surgery is highly effective, at the individual level, clinical response is highly variable. There are profound anatomical differences between RYGB and SG which in turn impact upon the mechanisms underlying the weight-reducing effects of these two procedures. Gut hormones, BA, gut microbiota and other mechanisms, many of them to be identified yet, contribute to the durability of decreased appetite and the sustainable weight loss following both RYGB and SG. Studies comparing weight loss suggest that after 3 years, a subtle weight loss difference may exist in favour of RYGB. Recent data suggest that longer-term health improvements are related to the degree of sustained weight loss achieved, thus highlighting the need to maximise post-surgery weight loss. A greater understanding of the procedure-related mechanisms and interaction with a person's genetics and pre-surgery phenotype will allow surgical procedure choice to be tailored to the individual to maximise the weight loss and metabolic outcomes, and will facilitate the discovery of novel non-surgical treatments for people with obesity.

Acknowledgements The authors would like to thank Chiara Bullo for the illustrations, and Friedrich Jassil and Cormac McGee for their critical review of the manuscript.

\section{Compliance with ethical standards}

Funding No funding.

Conflict of interest All authors declare that they have no conflict of interest. 
Ethical approval All procedures performed in studies involving human participants were in accordance with the ethical standards of the institutional and national research committee and with the 1964 Helsinki declaration and its later amendments or comparable ethical standards.

Informed consent Informed consent was obtained from all individual participants included in the studies performed by the authors.

Open Access This article is distributed under the terms of the Creative Commons Attribution 4.0 International License (http://creativeco mmons.org/licenses/by/4.0/), which permits unrestricted use, distribution, and reproduction in any medium, provided you give appropriate credit to the original author(s) and the source, provide a link to the Creative Commons license, and indicate if changes were made.

\section{References}

1. WHO Global health observatory (GHO) data 2016 Available from: http://www.who.int/gho/ncd/risk_factors/overweight _obesity/obesity_adults/en/

2. Gloy VL, Briel M, Bhatt DL et al (2013) Bariatric surgery versus non-surgical treatment for obesity: a systematic review and meta-analysis of randomised controlled trials. BMJ 347:f5934. https://doi.org/10.1136/bmj.f5934 (clinical research ed)

3. Makaronidis JM, Batterham RL (2016) Potential mechanisms mediating sustained weight loss following Roux-en-Y gastric bypass and sleeve gastrectomy. Endocrinol Metab Clin North Am 45(3):539-552. https://doi.org/10.1016/j.ecl.2016.04.006

4. Schauer PR, Bhatt DL, Kirwan JP et al (2017) Bariatric surgery versus intensive medical therapy for diabetes-5-year outcomes. N Engl J Med 376(7):641-651. https://doi.org/10.1056/NEJMo a1600869

5. Sjostrom L (2013) Review of the key results from the Swedish Obese Subjects (SOS) trial-a prospective controlled intervention study of bariatric surgery. J Intern Med 273(3):219-234. https://doi.org/10.1111/joim.12012

6. Radaelli MG, Martucci F, Perra S et al (2017) NAFLD/NASH in patients with type 2 diabetes and related treatment options. J Endocrinol Invest. https://doi.org/10.1007/s40618-017-0799-3

7. Saber AA, Elgamal MH, McLeod MK (2008) Bariatric surgery: the past, present, and future. Obes Surg 18(1):121-128. https:// doi.org/10.1007/s11695-007-9308-7

8. Payne JH, Dewind LT, Commons RR (1963) Metabolic observations in patients with jejunocolic shunts. Am J Surg 106:273-289

9. Sherman CD Jr, May AG, Nye W et al (1965) Clinical and metabolic studies following bowel by-passing for obesity. Ann N Y Acad Sci 131(1):614-622

10. Buchwald H (2014) The evolution of metabolic/bariatric surgery. Obes Surg 24(8):1126-1135. https://doi.org/10.1007/s1169 5-014-1354-3

11. Mason EE, Ito C (1967) Gastric bypass in obesity. Surg Clin N Am 47(6):1345-1351

12. Angrisani L, Santonicola A, Iovino P et al (2017) Bariatric surgery and endoluminal procedures: IFSO worldwide survey 2014. Obes Surg 27(9):2279-2289. https://doi.org/10.1007/s1169 5-017-2666-X

13. Manning S, Pucci A, Carter NC et al (2015) Early postoperative weight loss predicts maximal weight loss after sleeve gastrectomy and Roux-en-Y gastric bypass. Surg Endosc 29(6):1484-1491. https://doi.org/10.1007/s00464-014-3829-7
14. Pucci A, Tymoszuk U, Cheung WH et al (2018) Type 2 diabetes remission 2 years post Roux-en-Y gastric bypass and sleeve gastrectomy: the role of the weight loss and comparison of DiaRem and DiaBetter scores. Diabet Med J Br Diabet Assoc 35(3):360 367. https://doi.org/10.1111/dme.13532

15. Olbers T, Lonroth H, Fagevik-Olsen M et al (2003) Laparoscopic gastric bypass: development of technique, respiratory function, and long-term outcome. Obes Surg 13(3):364-370. https://doi. org/10.1381/096089203765887679

16. Abu-Jaish W, Rosenthal RJ (2010) Sleeve gastrectomy: a new surgical approach for morbid obesity. Expert Rev Gastroenterol Hepatol 4(1):101-119. https://doi.org/10.1586/egh.09.68

17. Halperin F, Ding SA, Simonson DC et al (2014) Roux-en-Y gastric bypass surgery or lifestyle with intensive medical management in patients with type 2 diabetes: feasibility and 1-year results of a randomized clinical trial. JAMA Surg 149(7):716-726. https:// doi.org/10.1001/jamasurg.2014.514

18. Courcoulas AP, Belle SH, Neiberg RH et al (2015) Three-year outcomes of bariatric surgery vs lifestyle intervention for type 2 diabetes mellitus treatment: a randomized clinical trial. JAMA Surg 150(10):931-940. https://doi.org/10.1001/jamasurg.2015.1534

19. Schauer PR, Bhatt DL, Kirwan JP et al (2014) Bariatric surgery versus intensive medical therapy for diabetes-3-year outcomes. $\mathrm{N}$ Engl J Med 370(21):2002-2013. https://doi.org/10.1056/NEJMo a1401329

20. Peterli R, Wolnerhanssen BK, Peters T et al (2018) Effect of laparoscopic sleeve gastrectomy vs laparoscopic Roux-en-Y gastric bypass on weight loss in patients with morbid obesity: the SMBOSS randomized clinical trial. JAMA 319(3):255-265. https:// doi.org/10.1001/jama.2017.20897

21. Salminen P, Helmio M, Ovaska J et al (2018) Effect of laparoscopic sleeve gastrectomy vs laparoscopic Roux-en-Y Gastric bypass on weight loss at 5 years among patients with morbid obesity: the SLEEVEPASS randomized clinical trial. JAMA 319(3):241-254. https://doi.org/10.1001/jama.2017.20313

22. Ignat M, Vix M, Imad I et al (2017) Randomized trial of Rouxen-Y gastric bypass versus sleeve gastrectomy in achieving excess weight loss. Br J Surg 104(3):248-256. https://doi.org/10.1002/ bjs. 10400

23. Osland E, Yunus RM, Khan S et al (2017) Weight loss outcomes in laparoscopic vertical sleeve gastrectomy (LVSG) versus laparoscopic Roux-en-Y gastric bypass (LRYGB) procedures: a metaanalysis and systematic review of randomized controlled trials. Surg Laparosc Endosc Percutaneous Tech 27(1):8-18. https://doi. org/10.1097/sle.0000000000000374

24. Kashyap SR, Bhatt DL, Wolski K et al (2013) Metabolic effects of bariatric surgery in patients with moderate obesity and type 2 diabetes: analysis of a randomized control trial comparing surgery with intensive medical treatment. Diabetes Care 36(8):2175-2182. https://doi.org/10.2337/dc12-1596

25. Miras AD, le Roux CW (2013) Mechanisms underlying weight loss after bariatric surgery. Nat Rev Gastroenterol Hepatol 10(10):575-584. https://doi.org/10.1038/nrgastro.2013.119

26. Makaronidis JM, Batterham RL (2018) Obesity, body weight regulation and the brain: insights from fMRI. Br J Radiol. https:// doi.org/10.1259/bjr.20170910

27. Scott WR, Batterham RL (2011) Roux-en-Y gastric bypass and laparoscopic sleeve gastrectomy: understanding weight loss and improvements in type 2 diabetes after bariatric surgery. Am J Physiol Regul Integr Comp Physiol 301(1):R15-R27. https://doi. org/10.1152/ajpregu.00038.2011

28. Batterham RL, Cowley MA, Small CJ et al (2002) Gut hormone PYY(3-36) physiologically inhibits food intake. Nature 418(6898):650-654. https://doi.org/10.1038/nature02666

29. Manning S, Pucci A, Batterham RL (2015) GLP-1: a mediator of the beneficial metabolic effects of bariatric surgery? Physiology 
(Bethesda, Md) 30(1):50-62. https://doi.org/10.1152/physi ol.00027.2014

30. Batterham RL, Ffytche DH, Rosenthal JM et al (2007) PYY modulation of cortical and hypothalamic brain areas predicts feeding behaviour in humans. Nature 450(7166):106-109. https://doi. org/10.1038/nature06212

31. Guida C, Stephen S, Guitton R et al (2017) The role of PYY in pancreatic islet physiology and surgical control of diabetes. Trends Endocrinol Metab TEM 28(8):626-636. https://doi. org/10.1016/j.tem.2017.04.005

32. Pucci A, Finer N (2015) New medications for treatment of obesity: metabolic and cardiovascular effects. Can J Cardiol 31(2):142152. https://doi.org/10.1016/j.cjca.2014.11.010

33. Muller TD, Nogueiras R, Andermann ML et al (2015) Ghrelin. Mol Metab 4(6):437-460. https://doi.org/10.1016/j.molme t.2015.03.005

34. Berthoud HR (2011) Metabolic and hedonic drives in the neural control of appetite: who is the boss? Curr Opin Neurobiol 21(6):888-896. https://doi.org/10.1016/j.conb.2011.09.004

35. Seeley RJ, Chambers AP, Sandoval DA (2015) The role of gut adaptation in the potent effects of multiple bariatric surgeries on obesity and diabetes. Cell Metab 21(3):369-378. https://doi. org/10.1016/j.cmet.2015.01.001

36. Thomas C, Gioiello A, Noriega L et al (2009) TGR5-mediated bile acid sensing controls glucose homeostasis. Cell Metab 10(3):167-177. https://doi.org/10.1016/j.cmet.2009.08.001

37. Dufer M, Horth K, Wagner R et al (2012) Bile acids acutely stimulate insulin secretion of mouse beta-cells via farnesoid $\mathrm{X}$ receptor activation and K(ATP) channel inhibition. Diabetes 61(6):1479_ 1489. https://doi.org/10.2337/db11-0815

38. Lundasen T, Galman C, Angelin B et al (2006) Circulating intestinal fibroblast growth factor 19 has a pronounced diurnal variation and modulates hepatic bile acid synthesis in man. J Intern Med 260(6):530-536. https://doi.org/10.1111/j.1365-2796.2006.01731 .x

39. Fang S, Suh JM, Reilly SM et al (2015) Intestinal FXR agonism promotes adipose tissue browning and reduces obesity and insulin resistance. Nat Med 21(2):159-165. https://doi.org/10.1038/ nm.3760

40. Watanabe M, Houten SM, Mataki C et al (2006) Bile acids induce energy expenditure by promoting intracellular thyroid hormone activation. Nature 439(7075):484-489. https://doi. org/10.1038/nature04330

41. Suzuki T, Aoyama J, Hashimoto M et al (2014) Correlation between postprandial bile acids and body fat mass in healthy normal-weight subjects. Clin Biochem 47(12):1128-1131. https ://doi.org/10.1016/j.clinbiochem.2014.04.025

42. Turnbaugh PJ, Ley RE, Hamady M et al (2007) The human microbiome project. Nature 449(7164):804-810. https://doi. org/10.1038/nature06244

43. Martinez KB, Pierre JF, Chang EB (2016) The gut microbiota: the gateway to improved metabolism. Gastroenterol Clin N Am 45(4):601-614. https://doi.org/10.1016/j.gtc.2016.07.001

44. Cummings DE (2015) Taste and the regulation of food intake: it's not just about flavor. Am J Clin Nutr 102(4):717-718. https ://doi.org/10.3945/ajen.115.120667

45. Piaggi P, Vinales KL, Basolo A et al (2018) Energy expenditure in the etiology of human obesity: spendthrift and thrifty metabolic phenotypes and energy-sensing mechanisms. J Endocrinol Invest 41(1):83-89. https://doi.org/10.1007/s40618-017-0732-9

46. Glicksman C, Pournaras DJ, Wright M et al (2010) Postprandial plasma bile acid responses in normal weight and obese subjects. Ann Clin Biochem 47(Pt 5):482-484. https://doi.org/10.1258/ acb.2010.010040

47. Aron-Wisnewsky J, Clement K (2014) The effects of gastrointestinal surgery on gut microbiota: potential contribution to improved insulin sensitivity. Curr Atheroscler Rep 16(11):454. https://doi.org/10.1007/s11883-014-0454-9

48. Turnbaugh PJ, Hamady M, Yatsunenko T et al (2009) A core gut microbiome in obese and lean twins. Nature 457(7228):480 484. https://doi.org/10.1038/nature07540

49. Turnbaugh PJ, Ridaura VK, Faith JJ et al (2009) The effect of diet on the human gut microbiome: a metagenomic analysis in humanized gnotobiotic mice. Sci Transl Med 1(6):6ra14. https ://doi.org/10.1126/scitranslmed.3000322

50. Backhed F, Ding H, Wang T et al (2004) The gut microbiota as an environmental factor that regulates fat storage. Proc Natl Acad Sci USA 101(44):15718-15723. https://doi.org/10.1073/ pnas.0407076101

51. Tambo A, Roshan MH, Pace NP (2016) The microbial hypothesis: contributions of adenovirus infection and metabolic endotoxaemia to the pathogenesis of obesity. Int J Chronic Dis 2016:7030795. https://doi.org/10.1155/2016/7030795

52. Turnbaugh PJ, Ley RE, Mahowald MA et al (2006) An obesityassociated gut microbiome with increased capacity for energy harvest. Nature 444(7122):1027-1031. https://doi.org/10.1038/ nature 05414

53. Barkeling B, King NA, Naslund E et al (2007) Characterization of obese individuals who claim to detect no relationship between their eating pattern and sensations of hunger or fullness. Int J Obes (2005) 31(3):435-439. https://doi.org/10.1038/ sj.ijo.0803449

54. Sumithran P, Prendergast LA, Delbridge E et al (2011) Longterm persistence of hormonal adaptations to weight loss. N Engl J Med 365(17):1597-1604. https://doi.org/10.1056/NEJMo a1105816

55. Leibel RL, Hirsch J (1984) Diminished energy requirements in reduced-obese patients. Metab Clin Exp 33(2):164-170

56. Browning KN, Fortna SR, Hajnal A (2013) Roux-en-Y gastric bypass reverses the effects of diet-induced obesity to inhibit the responsiveness of central vagal motoneurones. J Physiol 591(9):2357-2372. https://doi.org/10.1113/jphysiol.2012.249268

57. Mann T, Tomiyama AJ, Westling E et al (2007) Medicare's search for effective obesity treatments: diets are not the answer. Am Psychol 62(3):220-233. https://doi.org/10.1037/0003-066x.62.3.220

58. Ionut V, Bergman RN (2011) Mechanisms responsible for excess weight loss after bariatric surgery. J Diabetes Sci Technol 5(5):1263-1282. https://doi.org/10.1177/193229681100500536

59. Odstrcil EA, Martinez JG, Santa Ana CA et al (2010) The contribution of malabsorption to the reduction in net energy absorption after long-limb Roux-en-Y gastric bypass. Am J Clin Nutr 92(4):704-713. https://doi.org/10.3945/ajen.2010.29870

60. Manning S, Pucci A, Batterham RL (2015) Roux-en-Y gastric bypass: effects on feeding behavior and underlying mechanisms. J Clin Investig 125(3):939-948. https://doi.org/10.1172/jci76305

61. Dar MS, Chapman WH 3rd, Pender JR et al (2012) GLP-1 response to a mixed meal: what happens 10 years after Roux-enY gastric bypass (RYGB)? Obes Surg 22(7):1077-1083. https:// doi.org/10.1007/s11695-012-0624-1

62. Yousseif A, Emmanuel J, Karra E et al (2014) Differential effects of laparoscopic sleeve gastrectomy and laparoscopic gastric bypass on appetite, circulating acyl-ghrelin, peptide YY336 and active GLP-1 levels in non-diabetic humans. Obes Surg 24(2):241-252. https://doi.org/10.1007/s11695-013-1066-0

63. Cummings DE, Weigle DS, Frayo RS et al (2002) Plasma ghrelin levels after diet-induced weight loss or gastric bypass surgery. $\mathrm{N}$ Engl J Med 346(21):1623-1630. https://doi.org/10.1056/NEJMo a012908

64. Chandarana K, Drew ME, Emmanuel J et al (2009) Subject standardization, acclimatization, and sample processing affect gut hormone levels and appetite in humans. Gastroenterology 136(7):2115-2126. https://doi.org/10.1053/j.gastro.2009.02.047 
65. Dirksen C, Jorgensen NB, Bojsen-Moller KN et al (2013) Gut hormones, early dumping and resting energy expenditure in patients with good and poor weight loss response after Roux-enY gastric bypass. Int J Obes (2005) 37(11):1452-1459. https://doi. org/10.1038/ijo.2013.15

66. le Roux CW, Welbourn R, Werling M et al (2007) Gut hormones as mediators of appetite and weight loss after Roux-en-Y gastric bypass. Ann Surg 246(5):780-785. https://doi.org/10.1097/ SLA.0b013e3180caa3e3

67. Svane MS, Jorgensen NB, Bojsen-Moller KN et al (2016) Peptide YY and glucagon-like peptide-1 contribute to decreased food intake after Roux-en-Y gastric bypass surgery. Int J Obes (2005) 40(11):1699-1706. https://doi.org/10.1038/ijo.2016.121

68. Pucci A, Cheung WH, Jones J et al (2015) A case of severe anorexia, excessive weight loss and high peptide YY levels after sleeve gastrectomy. Endocrinol Diabetes Metab Case Rep 2015:150020. https://doi.org/10.1530/edm-15-0020

69. Rao RS, Kini S (2011) GIP and bariatric surgery. Obes Surg 21(2):244-252. https://doi.org/10.1007/s11695-010-0305-x

70. Salinari S, Bertuzzi A, Asnaghi S et al (2009) First-phase insulin secretion restoration and differential response to glucose load depending on the route of administration in type 2 diabetic subjects after bariatric surgery. Diabetes Care 32(3):375-380. https ://doi.org/10.2337/dc08-1314

71. Rubino F, Gagner M, Gentileschi P et al (2004) The early effect of the Roux-en-Y gastric bypass on hormones involved in body weight regulation and glucose metabolism. Ann Surg 240(2):236-242

72. Suzuki K, Jayasena CN, Bloom SR (2012) Obesity and appetite control. Exp Diabetes Res 2012:824305. https://doi. org/10.1155/2012/824305

73. Peterli R, Steinert RE, Woelnerhanssen B et al (2012) Metabolic and hormonal changes after laparoscopic Roux-en-Y gastric bypass and sleeve gastrectomy: a randomized, prospective trial. Obes Surg 22(5):740-748. https://doi.org/10.1007/s1169 5-012-0622-3

74. Jacobsen SH, Olesen SC, Dirksen C et al (2012) Changes in gastrointestinal hormone responses, insulin sensitivity, and beta-cell function within 2 weeks after gastric bypass in non-diabetic subjects. Obes Surg 22(7):1084-1096. https://doi.org/10.1007/s1169 5-012-0621-4

75. Sillakivi T, Suumann J, Kirsimagi U et al (2013) Plasma levels of gastric biomarkers in patients after bariatric surgery: biomarkers after bariatric surgery. Hepatogastroenterology 60(128):2129-2132

76. Egerod KL, Engelstoft MS, Grunddal KV et al (2012) A major lineage of enteroendocrine cells coexpress CCK, secretin, GIP, GLP-1, PYY, and neurotensin but not somatostatin. Endocrinology 153(12):5782-5795. https://doi.org/10.1210/en.2012-1595

77. Steinert RE, Peterli R, Keller S et al (2013) Bile acids and gut peptide secretion after bariatric surgery: a 1-year prospective randomized pilot trial. Obesity (Silver Spring, Md) 21(12):E660E668. https://doi.org/10.1002/oby.20522

78. Pournaras DJ, Glicksman C, Vincent RP et al (2012) The role of bile after Roux-en-Y gastric bypass in promoting weight loss and improving glycaemic control. Endocrinology 153(8):3613-3619. https://doi.org/10.1210/en.2011-2145

79. Ahmad NN, Pfalzer A (2005) Kaplan LM (2013) Roux-en-Y gastric bypass normalizes the blunted postprandial bile acid excursion associated with obesity. Int J Obes 37(12):1553-1559. https://doi. org/10.1038/ijo.2013.38

80. Liou AP, Paziuk M, Luevano JM Jr et al (2013) Conserved shifts in the gut microbiota due to gastric bypass reduce host weight and adiposity. Sci Transl Med 5(178):178141. https://doi.org/10.1126/ scitranslmed.3005687
81. Ryan KK, Tremaroli V, Clemmensen C et al (2014) FXR is a molecular target for the effects of vertical sleeve gastrectomy. Nature 509(7499):183-188. https://doi.org/10.1038/nature13135

82. Midtvedt T, Norman A, Nygaard K (1969) Bile acid transforming micro-organisms in rats with an intestinal blind segment. Acta Pathologica et microbiologica Scandinavica 77(1):162-166

83. Liu H, Hu C, Zhang X et al (2018) Role of gut microbiota, bile acids and their cross-talk in the effects of bariatric surgery on obesity and type 2 diabetes. J Diabetes Investig 9(1):13-20. https ://doi.org/10.1111/jdi.12687

84. Tremaroli V, Karlsson F, Werling M et al (2015) Roux-en-Y gastric bypass and vertical banded gastroplasty induce long-term changes on the human gut microbiome contributing to fat mass regulation. Cell Metab 22(2):228-238. https://doi.org/10.1016/j. cmet.2015.07.009

85. Furet JP, Kong LC, Tap J et al (2010) Differential adaptation of human gut microbiota to bariatric surgery-induced weight loss: links with metabolic and low-grade inflammation markers. Diabetes 59(12):3049-3057. https://doi.org/10.2337/db10-0253

86. Dethlefsen L, Relman DA (2011) Incomplete recovery and individualized responses of the human distal gut microbiota to repeated antibiotic perturbation. Proc Natl Acad Sci USA 108(Suppl 1):4554-4561. https://doi.org/10.1073/pnas.10000 87107

87. Murphy R, Tsai P, Jullig M et al (2017) Differential changes in gut microbiota after gastric bypass and sleeve gastrectomy bariatric surgery vary according to diabetes remission. Obes Surg 27(4):917-925. https://doi.org/10.1007/s11695-016-2399-2

88. Medina DA, Pedreros JP, Turiel D et al (2017) Distinct patterns in the gut microbiota after surgical or medical therapy in obese patients. PeerJ 5:e3443. https://doi.org/10.7717/peerj.3443

89. Guo Y, Liu CQ, Shan CX et al (2017) Gut microbiota after Roux-en-Y gastric bypass and sleeve gastrectomy in a diabetic rat model: increased diversity and associations of discriminant genera with metabolic changes. Diabetes/Metab Res Rev. https:// doi.org/10.1002/dmrr.2857

90. Cavin JB, Couvelard A, Lebtahi R et al (2016) Differences in alimentary glucose absorption and intestinal disposal of blood glucose after Roux-en-Y gastric bypass vs sleeve gastrectomy. Gastroenterology 150(2):454-464. https://doi.org/10.1053/j.gastr o.2015.10.009

91. Saeidi N, Meoli L, Nestoridi E et al (2013) Reprogramming of intestinal glucose metabolism and glycemic control in rats after gastric bypass. Science (New York, NY) 341(6144):406-410. https://doi.org/10.1126/science.1235103

92. Baud G, Daoudi M, Hubert T et al (2016) Bile diversion in Rouxen-Y gastric bypass modulates sodium-dependent glucose intestinal uptake. Cell Metab 23(3):547-553. https://doi.org/10.1016/j. cmet.2016.01.018

93. Zakeri R, Batterham RL (2018) Potential mechanisms underlying the effect of bariatric surgery on eating behaviour. Curr Opin Endocrinol Diabetes Obes 25(1):3-11. https://doi.org/10.1097/ med.0000000000000379

94. Berthoud HR (2008) Vagal and hormonal gut-brain communication: from satiation to satisfaction. Neurogastroenterol Motil 20(Suppl 1):64-72. https://doi.org/10.111 1/j.1365-2982.2008.01104.x

95. Berthoud HR, Shin AC, Zheng H (2011) Obesity surgery and gut-brain communication. Physiol Behav 105(1):106-119. https ://doi.org/10.1016/j.physbeh.2011.01.023

96. Leibel RL, Seeley RJ, Darsow T et al (2015) Biologic responses to weight loss and weight regain: report from an American diabetes association research symposium. Diabetes 64(7):2299-2309. https ://doi.org/10.2337/db15-0004 